\title{
RELATIONSHIP BETWEEN SHEAR PLANE OF THE FINAL PRESSING AND FATIGUE CRACK GROWTH BEHAVIOUR OF ROUND-BAR SPECIMENS OF CU PROCESSED BY ECAP
}

\author{
MASAHIRO GOTO ${ }^{1}$, TAKAEI YAMAMOTO ${ }^{1}$, SEUNG ZEON HAN ${ }^{2}$, JEE HYUK AHN ${ }^{2}$, \\ JUNICHI KITAMURA ${ }^{1}$, KUSNO KAMIL ${ }^{3}$, TERUTOSHI YAKUSHIJI ${ }^{4}$, TOSHIKI MASUDA ${ }^{1}$, \\ TAKASHI IWAMURA ${ }^{1} \&$ SANGSHIK KIM ${ }^{5}$ \\ ${ }^{1}$ Department of Mechanical Engineering, Oita University, Oita, Japan. \\ ${ }^{2}$ Korea Institute of Materials Science, Changwon, Republic of Korea. \\ ${ }^{3}$ Universitas Muslim Indonesia, Makassar, Indonesia. \\ ${ }^{4}$ National Institute of Technology, Oita College, Oita, Japan. \\ ${ }^{5}$ Gyeongsang National University, Chinju, Republic of Korea.
}

\begin{abstract}
The formation mechanism of inclined fatigue cracks in ultrafine-grained $\mathrm{Cu}$ processed by equal channel angular pressing was studied by using a smooth specimen with a small blind hole. The crack growth direction depended on the location of drilling hole along the circumferential direction of the round bar specimen and on the applied stress amplitudes. Although the low-cycle fatigue crack growth paths inclined $45^{\circ}$ and $90^{\circ}$ to the loading-axis were observed in the different locations on the surface, crack faces in these cracks were extended along one set of maximum shear stress planes, corresponding to the shear plane of the final processing. To study the crack growth behaviour, surface damage around the crack paths formed by the two-step fatigue stress tests was observed. Profile of crack face was examined, showing the aspect ratios (b/a) of $b / a=0.38$ and 1.10 for the cracks with $45^{\circ}$ and $90^{\circ}$ inclined path directions with respect to the loading axis, respectively. The role of the microstructure and deformation mode at the crack-tip areas on the formation of crack paths parallel to the shear plane of the final pressing was discussed in terms of the microstructural evolution caused by cyclic stressing and the mixed-mode stress intensity factor.

Keywords: copper, crack propagation, equal channel angular pressing, fatigue.
\end{abstract}

\section{INTRODUCTION}

Ultrafine grained (UFG) materials, having the grain sizes in the sub-micron and nanoscopic range, are of considerable interest. To date, many investigators have focused on optimizing processing conditions, on determining the underlying microstructural mechanisms, and on the static mechanical properties [1-5].

For the envisaged structural applications, extensive studies have been made on the fatigue crack growth behaviour of UFG metals and alloys processed by equal channel angular pressing (ECAP). For ECAP-prepared samples, the $y z-, z x$ - and $x y$-planes are defined by three mutually orthogonal planes of sectioning that lie perpendicular to the longitudinal axis of the pressed sample, and parallel to either the sample side, or the top faces at the point of exit from the die, respectively. In low-cycle fatigue tests, many investigators have showed that the crack in the $z x$ - and $x y$-plane created a $45^{\circ}-[6-8]$ and a $90^{\circ}$ - incline $[9,10]$ to the loading axis, respectively, and these crack path directions were parallel to the shear direction of the final ECAP processing. In addition, the growth rate of cracks in the $z x$-plane tended to be larger than that in the $x y$-plane [10]. Up to now, low-cycle fatigue (LCF) crack growth behaviour of UFG materials has been mainly discussed from the viewpoints of microstructure and morphological features of surface damage. On the other hand, the discussion from the mechanical viewpoints should be done for a better understanding of the fatigue damage of UFG materials. However, such studies are few and certain questions remain unanswered. 
In the present study, fatigue tests of copper $(99.99 \% \mathrm{Cu})$ processed by ECAP through eight passages were carried out. The objective of this study is to investigate the physical background of the formation of crack growth paths and fast crack growth in the $z x$-plane in terms of the mixed-mode deformation at the crack tip.

\section{EXPERIMENTAL PROCEDURES}

The material used was pure oxygen-free $(99.99 \mathrm{wt} \%) \mathrm{Cu}$. Before ECAP, the materials were annealed at $500^{\circ} \mathrm{C}$ for $1 \mathrm{~h}$ (grain size, $100 \mu \mathrm{m}$ ). The ECAP die had a $90^{\circ}$ angle between intersecting channels. The angles at the inner and outer corners of the channel intersection were $\Phi=90^{\circ}$ and $\Psi=45^{\circ}$, respectively. Repetitive ECAP was accomplished according to the Bc route (after each pressing, the billet bar was rotated $90^{\circ}$ around its longitudinal axis). Each rod was subjected to eight sequential passes of pressing at room temperature. $\mathrm{MoS}_{2}$ was used as a lubricant for each pressing, and the pressing speed was $5 \mathrm{~mm} / \mathrm{sec}$. The tensile test specimens were cylindrical, $4 \mathrm{~mm}$ in diameter and $40 \mathrm{~mm}$ long. The tensile tests were conducted on all the specimens at room temperature on an Instron-4208 testing machine at a strain rate of $1.6 \times 10^{-3} \mathrm{~s}^{-1}$. The pre-ECAP mechanical properties were $232 \mathrm{MPa}$ tensile strength, $65 \%$ elongation and Vickers hardness of 63 (load: $2.9 \mathrm{~N}$ ). After eight ECAP passages, the properties changed to $435 \mathrm{MPa}, 22.6 \%$, and 136, respectively. The grain size was measured using a transmission electron microscope. The average grain/cell size of ECAP-prepared samples was measured as $320 \mathrm{~nm}$, here for elongated grains; the thickness was measured as grain size and not as the diameter of equiaxed grains.

An analysis has shown that the equivalent strain, $\varepsilon$, after one pass is given by the following relationship [11]:

$$
\varepsilon=\frac{1}{\sqrt{3}}\left\{2 \cot \left(\frac{\Phi}{2}+\frac{\Psi}{2}\right)+\Psi \operatorname{cosec}\left(\frac{\Phi}{2}+\frac{\Psi}{2}\right)\right\} .
$$

Total of eight extrusion passes resulted in an equivalent strain of about 7.8.

Fatigue specimens $5 \mathrm{~mm}$ in diameter were machined from their respective processed bars. Although the specimens had a shallow circumferential notch $(20-\mathrm{mm}$ notch radius and 0.25 -mm notch depth), the fatigue strength reduction factor for this geometry was close to 1 , meaning that they could be considered plain. The fatigue specimens were electrolytically polished (approximately $\approx 25 \mu \mathrm{m}$ from the surface layer) prior to mechanical testing to remove any preparation-affected surface layer.

Figure 1 shows the location of monitoring areas and the definition of orientation of fatigue specimens relative to the final pressing plane described as a dark elliptical-area. The monitoring area was set on the middle surfaces where an intersection between the shear plane of the final pressing and the specimen surface makes an angle of $45^{\circ}$ (the $z x$-plane) or $90^{\circ}$ (the $x y$-plane) with respect to the loading axis. The fatigue damage and crack growth behaviour were monitored on both planes. Prior to testing, in some specimens, a small blind hole (both diameter and depth of $0.1 \mathrm{~mm}$ ) was drilled on the monitoring area as a crack starter. The cracks/hole on the $z x$ - and $x y$-planes are referred to hereafter as the ' $z x$-plane crack/hole' and ' $x y$-plane crack/hole', respectively.

All fatigue tests were performed at room temperature using a rotating-bending fatigue machine (constant bending-moment type) operating at $50 \mathrm{~Hz}$. The fatigue damage on the specimen surface was observed using an optical microscope (OM) and a scanning electron microscope (SEM). The crack length, $l$, was measured along the circumferential direction of the surface using a plastic replication technique. The stress value referred to is that of the nominal stress amplitude, $\sigma_{a}$, at the minimum cross-section (5-mm diameter). 


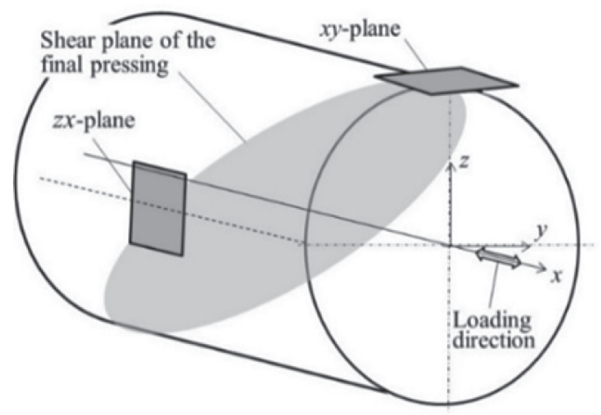

Figure 1: The location of monitoring areas and definition of orientation of fatigue specimens relative to the final pressing.

\section{EXPERIMENTAL RESULTS}

Figure 2 shows the crack growth paths in the $z x$ - and $x y$-planes under high- and low-stress amplitudes $\left(\sigma_{a}=240\right.$ and $\left.90 \mathrm{MPa}\right)$. At $\sigma_{a}=240 \mathrm{MPa}$, the $z x$-plane crack that initiated from the hole created a $45^{\circ}$ incline to the loading axis and this crack path direction was parallel to the shear direction of the final ECAP processing (Fig. 1). The $45^{\circ}$ inclined crack growth direction has been commonly observed in the $z x$-plane of LCF UFG metals [6-8]. However, the $x y$-plane crack grew nearly perpendicular to the loading axis. At $\sigma_{a}=90 \mathrm{MPa}$, on the other hand, the macroscale growth direction was perpendicular to the loading axis regardless of the plane where the crack initiated, nevertheless, the crack propagated in a zigzag manner at the microscale. There was no difference in the crack growth behaviour and the morphological features of surface damage around crack paths between the UFG and conventional grain-sized copper. This was because that the grain coarsening as a result of dynamic recrystallization due to a long term of cyclic stressing. Grain coarsening during fatigue is a time-, amplitude-, purity- and temperature-dependent microstructural process. It has been suggested that a certain time and cumulative strain are required for the release of sufficient stored strain energy to allow dislocation motion, recrystallization and subsequent grain coarsening [12].

To study the unique crack growth behaviour at a high-stress amplitude, the behaviour of microcrack initiation was monitored by using plane specimens (without a hole). Figure 3a and $b$ show the change in surface states around a fatal crack, which led to the final fracture of the specimen, in the $z x$ - and $x y$-planes under a high-stress amplitude $\left(\sigma_{a}=240 \mathrm{MPa}\right)$ corresponding to the LCF regime. In the $z x$-plane, at an early fatigue stage, a large number of shear bands (SBs) with a length of less than a few micrometres [13] were created a $45^{\circ}$ incline to the loading axis and this SB orientation was parallel to the shear plane of the final ECAP processing. Fatigue cracks were initiated from SBs and propagated along the SBs with a coalescence of microcracks generated in nearby SBs. It is reasonable to assume that the SB formation and microcrack growth were strongly affected by the microstructural inhomogeneity retained in the matrix because of the incomplete dynamic recovery/recrystallization. It has been shown that unlike the microstructure that evolved at $\sigma_{a}=90 \mathrm{MPa}$, the defect structure produced during ECAP processing should be still moderately retained in the matrix fatigued at $\sigma_{a}=240 \mathrm{MPa}[14,15]$. Indeed, among innumerable maximum shear stress planes, SBs and microcracks were initiated along one set of the maximum shear stress planes corresponding to the final ECAP shear plane. To successfully release the local high strain energy caused by the defects distributed along the final ECAP streamline, the maximum shear stress planes 
a

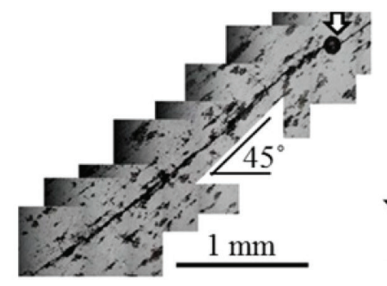

b

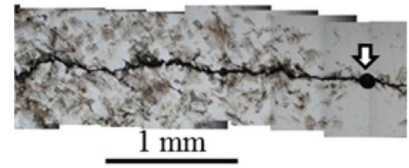

C

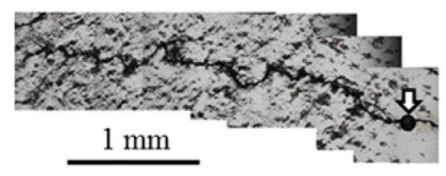

飞? : Blind hole

$\uparrow$ : Loading direction

d

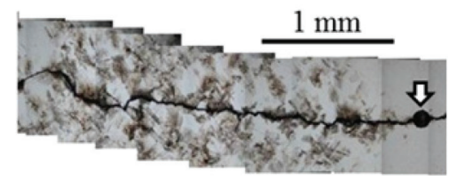

Figure 2: Effect of stress amplitudes on crack growth paths in the $z x$ - and $x y$-planes: (a and b) the $z x$-plane crack at $\sigma_{a}=240$ and $90 \mathrm{MPa}$; (c and d) the $x y$-plane crack at $\sigma_{a}=240$ and $90 \mathrm{MPa}$.

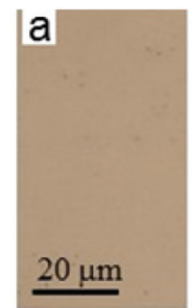

$N=0$

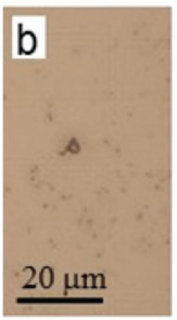

$N=0$

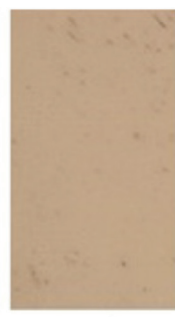

$10^{4}$

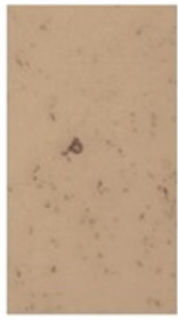

$10^{4}$

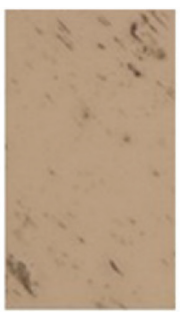

$3 \times 10^{4}$

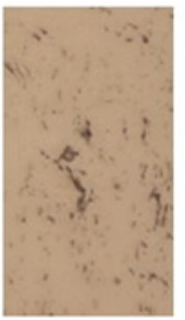

$3 \times 10^{4}$

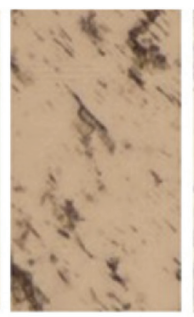

$5 \times 10^{4}$

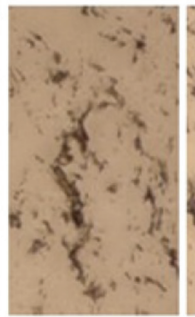

$5 \times 10^{4}$

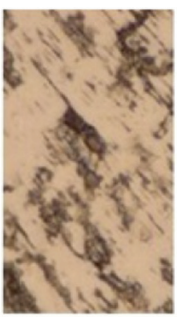

$7 \times 10^{4}$

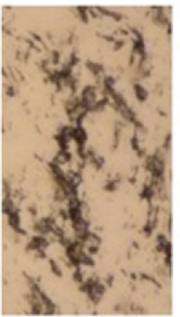

$7 \times 10^{4}$

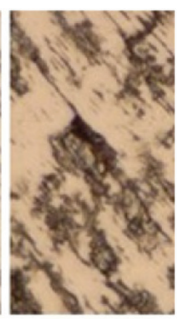

$9 \times 10^{4}$

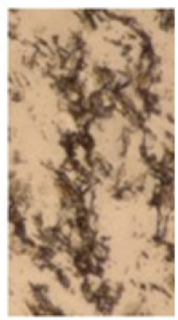

$9 \times 10^{4}$

Figure 3: OM micrograph showing the change in surface states around a fatal crack under cyclic stressing at $\sigma_{a}=240 \mathrm{MPa}$ : (a) the $z x$-plane; (b) the $x y$-plane.

corresponding to the final ECAP shear plane may be a reasonable selection. The fatigue tests of UFG $\mathrm{Cu}$ in the LCF regime showed the $45^{\circ}$ inclined crack paths in the $z x$-plane [6-10]. Regarding the $x y$-plane, the crack initiation and growth behaviour was like that observed for the $z x$-plane; however, the orientation of SBs and the crack growth direction were nearly perpendicular to the loading axis.

Figure 4 shows the crack growth curve of drilled specimens at $\sigma_{a}=240 \mathrm{MPa}$. For both planes, there was no distinct difference in the number of cycles required to initiate fatigue crack from the hole regardless of the location of drilling hole. The slop of growth curve was steeper in the $z x$-plane crack than the $x y$-plane crack for crack length of less than $1 \mathrm{~mm}$, however, the curves for crack length of longer than $1 \mathrm{~mm}$ had same slop for both planes. This is 


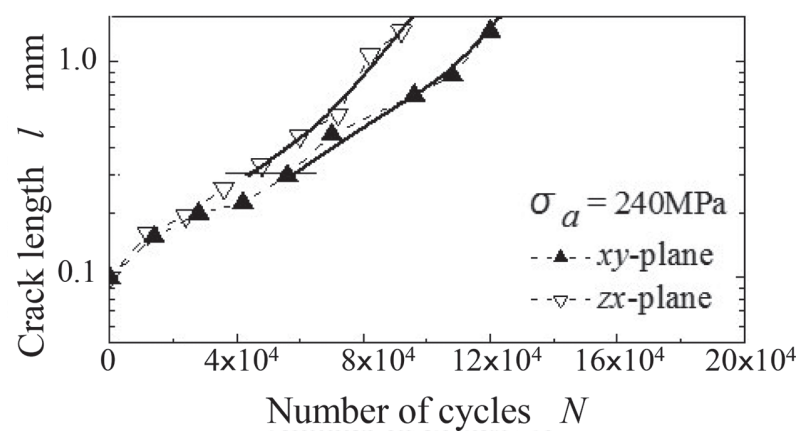

Figure 4: Crack growth curve of drilled specimens at $\sigma_{a}=240 \mathrm{MPa}$.

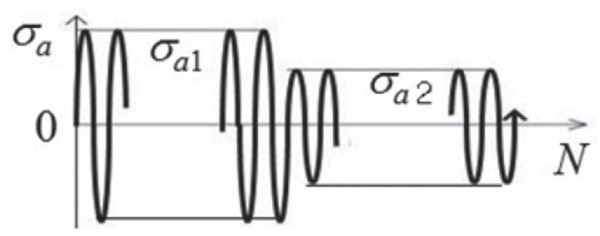

Figure 5: Loading pattern (high-to-low block stressing).

because that the assumption of the $z x$ - and $x y$-plane cracks holds for a limited area along the circumference of the specimen. For the present specimen with $5 \mathrm{~mm}$ diameter, the assumption appears to be meaningless for a long crack in excess of $l=1 \mathrm{~mm}$.

To clarify the difference in crack growth mechanism between the $z x$ - and $x y$-planes, twostep fatigue stress tests (Fig. 5) were conducted, i.e. after the formation of a crack with an arbitrary length at the high-stress amplitude $\left(\sigma_{a 1}\right)$, the crack continued to grow at the lowstress amplitude $\left(\sigma_{a 2}\right)$. Figure $6 \mathrm{a}$ and $\mathrm{b}$ shows the crack growth paths under two-step stress tests. For the $z x$-plane (Fig. 6a), a crack with a growth path at a $45^{\circ}$ incline to the loading axis was formed under $5.3 \times 10^{4}$ repetitions of $\sigma_{a 1}=240 \mathrm{MPa}$, leaving a linear crack path. After a stress amplitude change to $\sigma_{a 2}=90 \mathrm{MPa}$, the crack grew nearly perpendicular to the loading axis. For the $x y$-plane (Fig. $6 \mathrm{~b}$ ), the crack grew perpendicular to the loading axis under $6.0 \times$ $10^{4}$ repetitions of $\sigma_{a 1}=240 \mathrm{MPa}$. Under the second stress, the crack continued to grow perpendicular to the loading axis.

Figure 7 shows SEM micrograph of surface states around crack paths just before and after the stress change. Figure 7 a shows the surface damage in the $z x$-plane. The surface at the crack edges that were formed under high stress was comparatively flat, but the surface that formed under low stress had traces of localized plastic deformations, suggesting change in the crack growth mechanism between high and low stresses. Figure $7 \mathrm{~b}$ shows the surface damage in the $x y$-plane. Before the stress change, the crack paths showed severe zigzag manner. The traces of heavy localized plastic deformations were left around the crack paths. After the stress change, the crack continued to grow with zigzag manner, but the degree of zigzag was moderate as compared with that before the stress change.

To discuss the physical background of crack growth behaviour, the specimens were sectioned in the longitudinal direction (parallel to the $x$-axis), at specific crack lengths, followed 

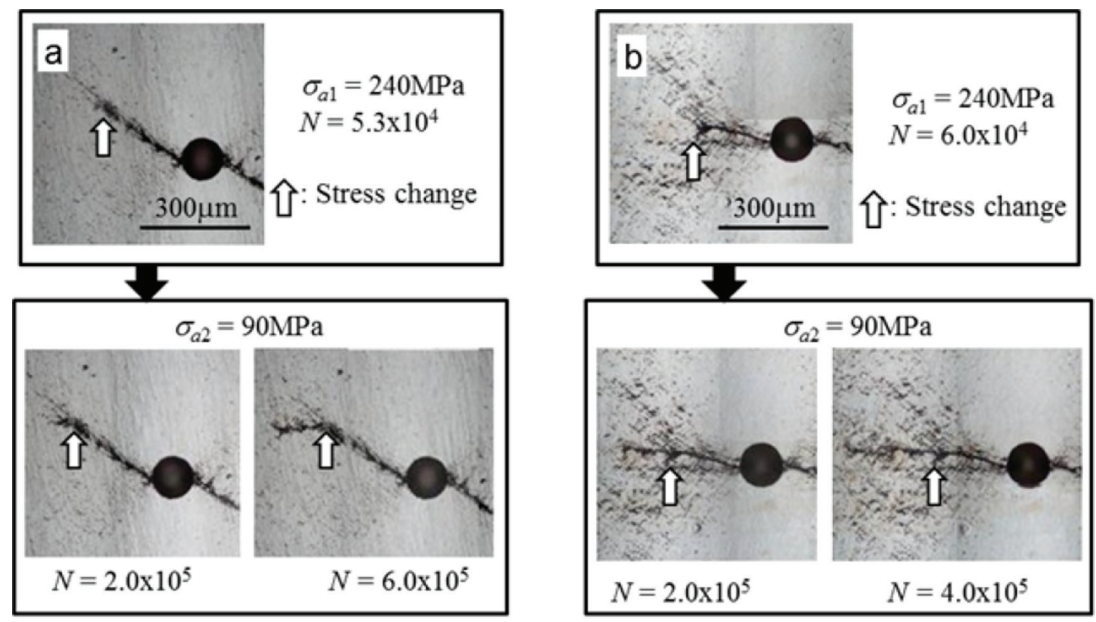

Figure 6: Crack growth paths under high-to-low block stressing: (a) the $z x$-plane crack; (b) the $x y$-plane crack.
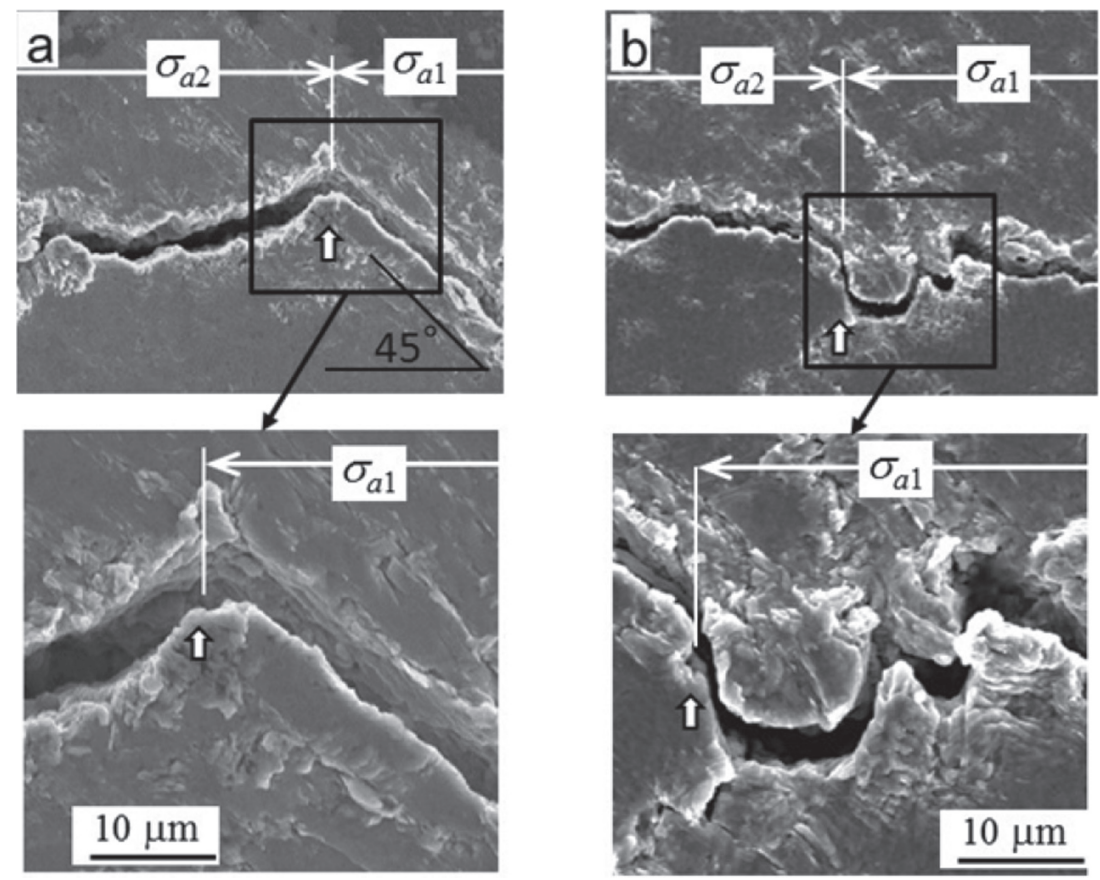

Figure 7: Surface state around the crack path just before and after the stress change $\left(\sigma_{a 1}=240\right.$ $\mathrm{MPa}, \sigma_{a 2}=90 \mathrm{MPa}(\mathrm{a})$ the $z x$-plane crack; (b) the $x y$-plane crack.

by etching of the sectioned planes. Figure 8 shows the crack growth paths formed at $\sigma_{a}=240$ $\mathrm{MPa}$ in the surface and the sectioned plane; (a) a $z x$-plane crack with 0.975 -mm length and (b) a $x y$-plane crack with 0.918 -mm length. The inner growth direction of the $z x$-plane crack was perpendicular to the surface. For the $x y$-plane cracks, the inner growth direction was inclined $45^{\circ}$ to the surface. Although the inclination direction of the crack path to the loading 
a

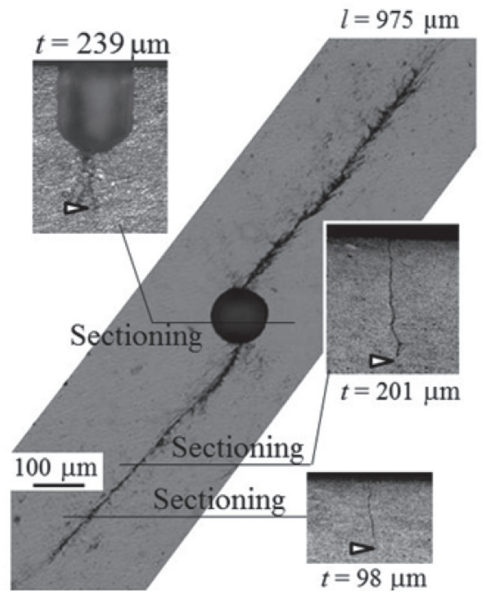

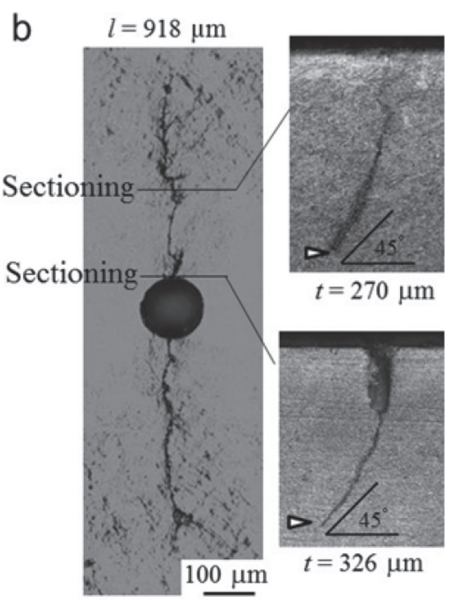

Figure 8: Sectioning position described in the crack paths on the surface and the inner growth paths under $\sigma_{a}=240 \mathrm{MPa}$ (a) a 0.975 -mm-long crack in the $z x$-plane; (b) a 0.918 -mm-long crack in the $x y$-plane.
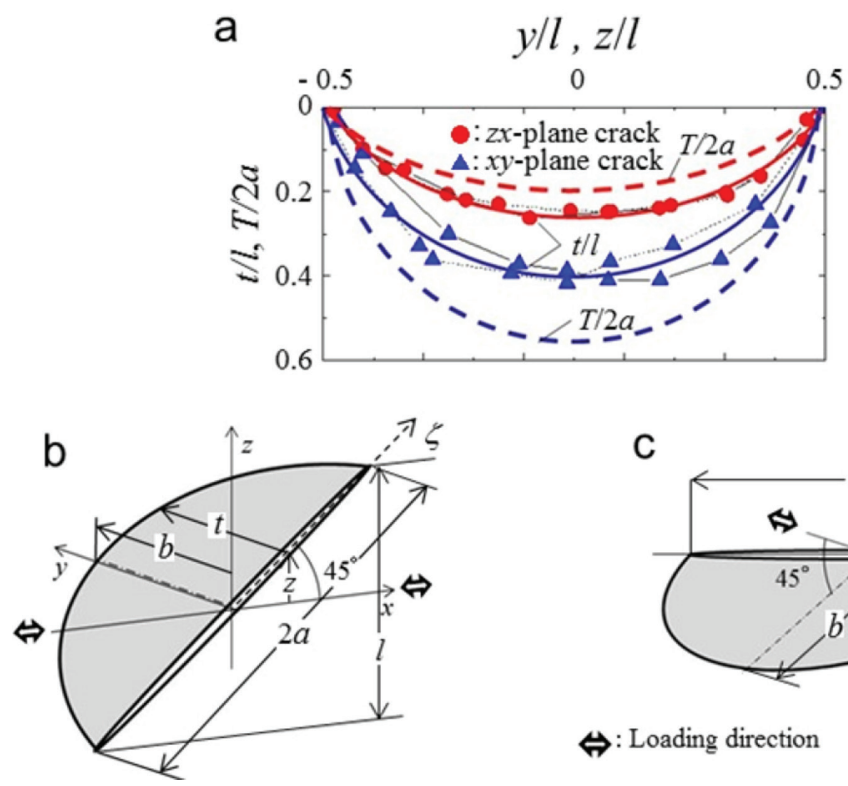

C

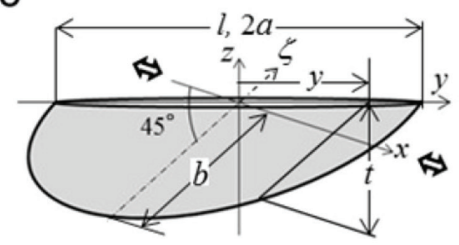

Loading direction

Figure 9: Schematics of crack growth behavior inside the specimen at $\sigma_{a}=240 \mathrm{MPa}$ : (a) crack face profile in terms of dimensionless sizes for the $z x$ - and $x y$-plane cracks; $(b, c)$ definition of the crack length/depth for an inclined crack on the $z x$-plane and a deflected crack on the $x y$-plane.

axis was different between the $z x$ - and $x y$-plane cracks, the paths for cracks in each plane were parallel to the shear plane of the final ECAP processing. Regarding the inner growth direction at low-stress amplitudes, like the crack paths commonly formed in the conventional grain-sized materials, the macroscale crack paths for the surface and sectioned planes were nearly perpendicular to the loading direction, regardless of the location of the hole [16]. 
Figure 9a shows the profile of the crack face, $y / l$ or $z / l$ versus $t / l$ relationship, where $t$ is the crack depth measured along the vertical direction to the specimen surface. The crack face shape was approximated by a semi-ellipse with the value of $t / l=0.266$ at the deepest point for the $z x$-plane crack and $t / l=0.389$ for the $x y$-plane crack. Considering the experimental results of Fig. 8, a declined surface-crack on the $z x$-plane and a deflected surface-crack on the $x y$-plane were defined as described in Figs $9 \mathrm{~b}$ and $\mathrm{c}$, where terms $a, T$ and $b$ are a half cracklength measured along the crack path direction, the crack depth measured along the crack face direction at a specific value of $y$ and $z$, and the maximum depth of a semielliptical crack measured along the crack face, respectively. A red- and a blue-dashed lines in Fig. 9a show the crack face profile for the $z x$ - and $x y$-plane cracks replotted by using a term $T / 2 a$ instead of $t / l$. The values of $b / a$, aspect ratio, were 0.378 for the $z x$-plane crack and 1.10 for the $x y$-plane crack. Incidentally, at a low-stress amplitude $\left(\sigma_{a}=90 \mathrm{MPa}\right)$, it has been shown that no deference in the crack face profile between the $z x$ - and $x y$-plane cracks and the aspect ratio was $b / a$ $=0.76$ which was nearly equivalent to the value of $b / a$ measured in annealed conventional grain-sized $\mathrm{Cu}[16]$.

\section{DISCUSSION}

To study the mechanical background of the unique crack growth directions of UFG $\mathrm{Cu}$ from the viewpoints of the deformation mode at the crack tip, the stress intensity factor (SIF) values were evaluated, by assuming a semi-infinite body with inclined semi-elliptical surface cracks, subjected to tension stress in the $x$-direction at infinity. The applied tension stress is resolved into two stress components perpendicular and tangential to the crack face. Accordingly, a $45^{\circ}$ inclined surface crack is subjected to both normal, $\sigma(=1)$, and shear stress, $\tau(=1)$, as illustrated in Figs 10a and b. Noda et al. [17] analyzed the SIFs of a semielliptical surface-crack subjected to modes I, II and III loading. The values of dimensionless SIF (DL-SIF), $F_{\text {I }}, F_{\text {II }}, F_{\text {III }}$, for the current surface-crack were taken from Noda's solution calculated for Poisson's ratio: $v=0.3$. The DL-SIF, $F_{\mathrm{I}}(\alpha), F_{\mathrm{II}}(\alpha), F_{\mathrm{III}}(\alpha)$, were defined as;

$$
F_{i}(\alpha)=\frac{K_{i}(\alpha)}{K_{i E}(\alpha)} \quad i=\text { I, II, III } .
$$

where $K_{i}(\alpha)$ is SIF along the crack front and $K_{i E}(\alpha)$ is SIF of an elliptical crack [17]. The location along a crack front was defined by the eccentric angle of the ellipse, $\alpha$, defined as the

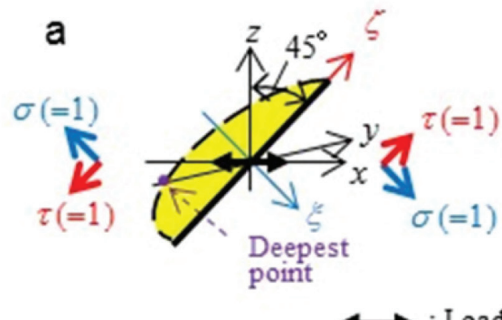

: Loading direction

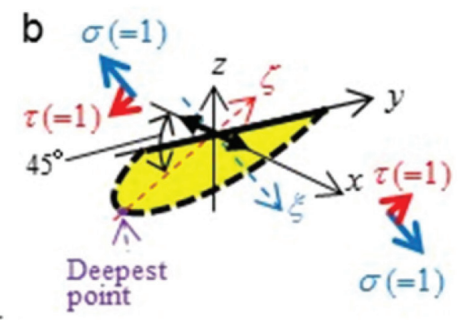

Figure 10: Inclined semi-elliptical surface cracks in a semi-infinite body subjected to tension load in the $x$-direction at infinity: (a) a model for a surface crack on the $z x$-plane; (b) a model for a surface crack on the $x y$-plane. 
angle for mapping a semi-circle [17]. The crack front at the surface and the deepest point are shown by $\alpha=0$ and $90^{\circ}$, respectively. However, the DL-SIF values at the surface were evaluated by the values at $\alpha=1^{\circ}$ instead of $\alpha=0^{\circ}$, because in three-dimensional surface cracks, the point where the crack front intersects a free surface is known as a corner point. The stress singularity at this point is different from that of an ordinary crack [18].

Table 1 shows the DL-SIF values of cracks with the aspect ratio, $b / a=0.38$ for the $z x$-plane crack, and 1.1 for the $x y$-plane crack, which are given from Fig. 9. The value of $F_{\mathrm{I}}$ for the $z x$-plane crack is larger at the crack bottom $\left(\alpha=90^{\circ}\right)$ than at the surface $\left(\alpha=1^{\circ}\right)$, giving rise to an aspect ratio larger than 1 . However, the actual aspect ratio was much smaller than 1 . Regarding the $F_{\text {II }}$, the large $F_{\text {II }}$ value $(=0.77)$ at the surface promotes in-plane shear mode crack growth. At the bottom, $F_{\text {III }}$ takes a value of 0.83 , but it seems reasonable to assume that antiplane shear mode deformation at the deepest point is negligible for the inward crack growth. Consequently, the $z x$-plane crack predominantly propagated at the surface due to in-plane shear mode deformation, which brings the generation of new SBs and extension of preexistent SBs around the crack tip areas, producing an aspect ratio much smaller than 1 . The tensile-mode deformation reflected by large $F_{\mathrm{I}}$ values should play the role of crack growth. From the perspective of the formation of the shallow semielliptical cracks, the tensile-mode deformation might assist shear mode growth, through the debonding of SBs around the crack tip $[15,19]$.

For the $x y$-plane crack (Table 2), the $F_{\mathrm{I}}$ value at the surface was 0.74 , i.e. larger than 0.60 at the bottom. This should lead to a superior extension of crack length, compared with the crack depth $(b / a<1)$. However, the actual crack extension was accelerated at the bottom, rather than at the surface. On the other hand, the $F_{\text {II }}$ value was higher at the bottom $(0.53)$ than at the surface $(-0.08)$, suggesting the deep semielliptical shape of the $x y$-plane crack caused by the in-plane shear mode deformation at the bottom. At the surface, mode-I crack growth appeared to be predominant, because of negligible values of $F_{\mathrm{II}}$ and $F_{\mathrm{III}}$. Therefore, mode-II crack growth plays an important role in determining the crack face shape.

The unique growth direction of microcracks at high stresses was attributed to inhomogeneous microstructures due to ECAP; microcracks initiated from SBs grew along the maximum shear stress plane corresponding to the shear plane of the final pressing, resulting in the inclined semielliptical surface cracks. As the crack grew, although the contribution of microstructural inhomogeneity on crack growth weakened, in-plane shear-mode deformation at the

Table 1: Dimensionless stress intensity factors for the $z x$-plane crack $(b / a=0.38)$.

\begin{tabular}{lllll}
\hline Type of crack & $\alpha(\mathrm{deg})$ & $\mathrm{F}_{\mathrm{I}}$ & $\mathrm{F}_{\mathrm{II}}$ & $\mathrm{F}_{\mathrm{III}}$ \\
\hline$z x$-plane crack & 1 & 0.68 & 0.77 & 0.31 \\
$b / a=0.38$ & 90 & 0.93 & 0 & 0.83 \\
\hline
\end{tabular}

Table 2: Dimensionless stress intensity factors for the $x y$-plane crack $(b / a=1.10)$.

\begin{tabular}{lllll}
\hline Type of crack & $\alpha(\mathrm{deg})$ & $\mathrm{F}_{\mathrm{I}}$ & $\mathrm{F}_{\mathrm{II}}$ & $\mathrm{F}_{\text {III }}$ \\
\hline$x y$-plane crack & 1 & 0.74 & -0.08 & 0.09 \\
$b / a=1.10$ & 90 & 0.60 & 0.53 & 0 \\
\hline
\end{tabular}


crack tip promoted the formation of a large inclined crack with a unique face profile. The fast crack growth rate in the $z x$-plane crack resulted from in-plane shear mode deformation in addition to the tensile mode deformation.

As indicated in Fig. 7b, the crack paths in the $x y$-plane under high stress showed a heavy zigzag manner. The zigzag growth paths were formed by the coalescence in preexistent SBs around the crack paths under the tensile mode deformation (The ND-SIF values were $F_{\mathrm{I}}=0.74, F_{\mathrm{II}}(=-0.08)$ and $\left.F_{\mathrm{III}}(=0.09)\right)$. The retarded crack growth on the $x y$-plane was therefore believed to be due to enhanced roughness-induced crack closure. For the $z x$-plane crack, the crack paths at high-stress amplitude $\left(\sigma_{a}=240 \mathrm{MPa}\right)$ were linear (Fig. 7a) because of the coalescence of pre-existent collinear-SBs/shear-cracks ahead of the crack tip under in-plane shear mode deformation $\left(F_{\text {II }}=0.77\right)$. This should contribute to the acceleration of the $z x$-plane crack.

\section{CONCLUSIONS}

The main findings of this study on the formation mechanism of inclined surface cracks in UFG copper can be summarized as follows:

1. At high-stress amplitudes, the crack path/face in both $z x$ - and $x y$-planes was extended along one set of the maximum shear stress planes, corresponding to the final ECAP shear plane, among innumerable maximum shear stress planes, showing a high microstructural sensitivity to crack-path formation. At low-stress amplitudes, the crack path was perpendicular to the loading direction regardless of the ECAP shear plane.

2. Two-step stress tests indicated that the surface at the $z x$-plane crack edges that were formed under high stress was comparatively flat, whereas the surface around the $x y$ plane crack paths showed traces of severe plastic deformation, meaning a difference in predominant crack growth mechanism: shear mode for the former and tensile mode for the later.

3. At high-stress amplitudes, the cracks in the $z x$ - and $x y$-planes had a shallow and deep semielliptical face, respectively. The normal aspect ratio, $b / a$, was 0.38 for the $z x$ - and 1.1 for the $x y$-plane cracks. The inclined crack path and crack face profile were attributed to the inhomogeneity in ECAP microstructure and the in-plane shear-mode deformation around the crack-tip areas.

4. The fast crack growth rate in the $z x$-plane crack resulted from in-plane shear mode deformation in addition to the tensile mode deformation.

\section{ACKNOWLEDGEMENTS}

The authors wish to express their gratitude to Professor Nao-aki. Noda of the Kyushu Institute of Technology, Japan, for fruitful discussion on mixed-mode stress intensity factors. This study was supported by a Grant-in-Aid for Scientific Research (C) (KAKENHI: No. 26420021) from the Japan Society for the Promotion of Science, as well as a National Research Foundation of Korea (NRF) grant funded by the Global Frontier R\&D Program (2013M3A6B1078874) at the Global Frontier Hybrid Interface Materials R\&D Centre funded by the Ministry of Science, ICT, and a Future Planning and National Research Foundation of Korea (NRF) grant funded by the Korea government (MSIP) (no. 2011-0030058). The authors are very grateful to the members of the Strength of Materials Laboratory of Oita 
University for their excellent experimental assistance. Thanks are also extended to the members of the Korea Institute of Materials Science, for performing the ECAP processing of our copper rods.

\section{REFERENCES}

[1] Segal, V.M., Materials processing by simple shear. Materials Science \& Engineering: A, 197, pp. 157-164, 1995. https://doi.org/10.1016/0921-5093(95)09705-8

[2] Valiev, R.Z., Structure and mechanical properties of ultrafine-grained metals. Materials Science \& Engineering: A, 234-236, pp. 59-66, 1997. https://doi.org/10.1016/S0921-5093(97)00183-4

[3] Agnew, S.R. \& Weertman, J.R., Cyclic softening of ultrafine grain copper. Materials Science \& Engineering: A, 244, pp. 145-153, 1998. https://doi.org/10.1016/S0921-5093(97)00689-8

[4] Vinogradov, A. \& Hashimoto, S., Multiscale phenomena in fatigue of ultra-fine grain materials-an overview. Materials Transactions, 42, pp. 74-84, 2000. https://doi.org/10.2320/matertrans.42.74

[5] Brebbia, C.A., Telles, J.C.F. \& Wrobel, L.C., (eds), Boundary Element Techniques, Springer-Verlag: Berlin and New York, pp. 11-13, 1984.

[6] Höppel, H.W., Zhou, Z.M., Mughrabi, H. \& Valiev, R.Z., Microstructural study of the parameters governing coarsening and cyclic softening in fatigued ultrafine-grained copper. Philosophical Magazine -A, 82, pp. 1781-1794, 2002. https://doi.org/10.1080/01418610208235689

[7] Wu, S.D., Wang, Z.G., Jiang, C.B., Li, G.Y., Alexandrov, I.V. \& Valiev, R.Z., The formation of PSB-like shear bands in cyclically deformed ultrafine grained copper processed by ECAP. Scripta Materiala, 48, pp. 1605-1609, 2003. https://doi.org/10.1016/S1359-6462(03)00141-6

[8] Kunz, L., Lukáš, P. \& Svpboda, M., Fatigue strength, microstructural stability and strain localization in ultrafine-grained copper. Materials Science \& Engineering: A, 434, pp. 97-104, 2006.

https://doi.org/10.1016/j.msea.2006.02.029

[9] Fang, D., Zhang, P., Duan, Q., Wu, S., Zhang, Z., Li, J. \& Zhao, N., Fatigue behavior of Al-Cu alloy subjected to different number of ECAP passes. Advanced Engineering Materilas, 9, pp. 860-866, 2007.

https://doi.org/10.1002/adem.200700110

[10]Zhang, Z.F., Wu, D.S., Li, Y.J., Liu, S.M. \& Wang, Z.G., Cyclic deformation and fatigue properties of $\mathrm{Al}-0.7 \mathrm{wt} \% \mathrm{Cu}$ alloy produced by equal channel angular pressing. Materials Science \& Engineering, A, 412, pp. 279-286, 2005. https://doi.org/10.1016/j.msea.2005.08.221

[11] Goto, M., Han, S.Z., Ahn, J.H., Yakushiji, T., Euh, K., Kim, S.S. \& Lee, J., The role of mixed-mode deformation at the crack tip on shear banding and crack propagation of ultrafine-grained copper. International Journal of Fatigue, 66, pp. 220-228, 2014. https://doi.org/10.1016/j.ijfatigue.2014.04.007

[12] Iwahashi, Y., Wang, J., Horita, Z., Nemoto, M. \& Langdon, T.G., Principle of equalchannel angular pressing for the processing of ultra-fine grained materials. Scripta Materialia, 35, pp. 143-146, 1996. https://doi.org/10.1016/1359-6462(96)00107-8 
[13] Khatibi, G., Horky, J., Weiss, B. \& Zehetbauer, M.J., High cycle fatigue behavior of copper deformed by high pressure torsion. International Journal of Fatigue, 32, pp. 269-278, 2010. https://doi.org/10.1016/j.ijfatigue.2009.06.017

[14] Goto, M., Han, S.Z., Yakushiji, T., Lim, C.Y. \& Kim, S.S., Formation process of shear bands and protrusions in ultrafine grained copper under cyclic stresses. Scripta Materialia, 54, pp. 2101-2106, 2006.

https://doi.org/10.1016/j.scriptamat.2006.03.001

[15] Goto, M., Han, S.Z., Euh, K., Kang, J-H., Kim, S.S. \& Kawagoishi, N., Formation of a high-cycle fatigue fracture surface and a crack growth mechanism of ultrafine grained copper with different stages of microstructural evolution. Acta Materiala, 58, pp. 6294-6305, 2010.

https://doi.org/10.1016/j.actamat.2010.07.051

[16] Goto, M., Kamil, K., Han, S.Z., Euh, K., Kim, S.S. \& Lee, J., Fatigue-induced grain coarsening and crack growth behavior in ultrafine grained copper under different loading histories. International Journal of Fatigue, 51, pp. 57-67, 2013. https://doi.org/10.1016/j.ijfatigue.2013.02.008

[17] Goto, M., Han, S.Z., Yamamoto, T., Kitamura, J., Ahn, J.H., Yakushiji, T., Kim, S.S. \& Lee, J., Formation mechanism of inclined fatigue-cracks in ultrafine-grained $\mathrm{Cu}$ processed by equal channel angular pressing. International Journal of Fatigue, 92, pp. 577-587, 2016. https://doi.org/10.1016/j.ijfatigue.2016.02.006

[18] Noda, N.A. \& Kagita, M., Variations of stress intensity factors of a semi-elliptical surface crack subjected to mode I, II, III loading. International Journal of Pressure Vessels Piping, 81, pp. 635-644, 2004. https://doi.org/10.1016/j.ijpvp.2004.03.008

[19] Benthem, J.P., State of stress at the vertex of crack in a half-space. International Journal of Solids and Structures, 13, pp. 479-492, 1977. https://doi.org/10.1016/0020-7683(77)90042-7

[20] Zhang, J.Z., A shear band decohesion model for small fatigue crack growth in an ultrafine grain aluminium alloy. Engineering Fracture Mechanics, 65, pp. 665-681, 2000. https://doi.org/10.1016/S0013-7944(99)00148-4 